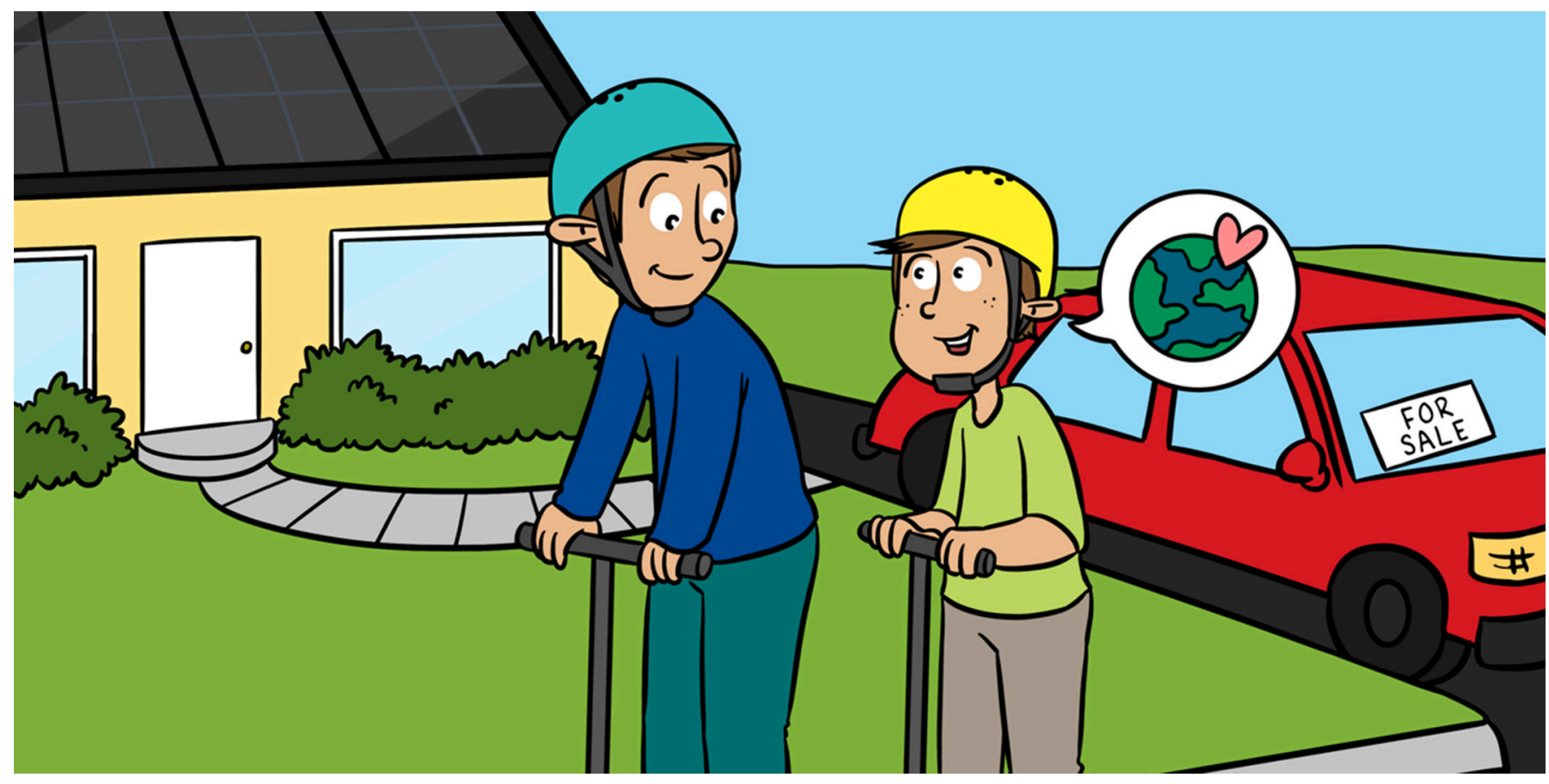

\title{
WHAT CAN WE DO TO ADDRESS CLIMATE CHANGE?
}

\section{Paloma Trascasa-Castro ${ }^{1^{*}}$ and Christopher J. Smith ${ }^{1,2}$ \\ ${ }^{1}$ School of Earth and Environment, University of Leeds, Leeds, United Kingdom \\ ${ }^{2}$ International Institute for Applied Systems Analysis, Laxenburg, Austria}

YOUNG REVIEWER:

(A) EVA

AGE: 12
Climate change is one of the most serious problems that humans face today, but until now progress in stopping it has been slow. Climate simulations show that Earth will only stop warming when we reach "net zero" emissions. This means that carbon dioxide $\left(\mathrm{CO}_{2}\right)$ emissions are cancelled out by an equal amount of greenhouse gas removal from the atmosphere. Worldwide efforts to achieve net zero emissions by 2050 are necessary to avoid some of the worst effects of climate change. Achieving net zero will require huge changes to our society. While there are some things we can all do to fight climate change, the biggest changes need to come from the way our businesses and countries are run, where we get our energy from, how we travel, and how much "stuff" we consume and waste. By taking urgent action, we can ensure the future well-being of billions of people worldwide. 
Figure 1

Expected global temperatures if we reach net zero by 2050 (purple) or by 2075 (green). Our current trend is shown in blue. The pledges made by countries in the Paris Agreement are not currently enough to meet the 2050 target and will result in around $3^{\circ} \mathrm{C}$ of warming by the end of the century.

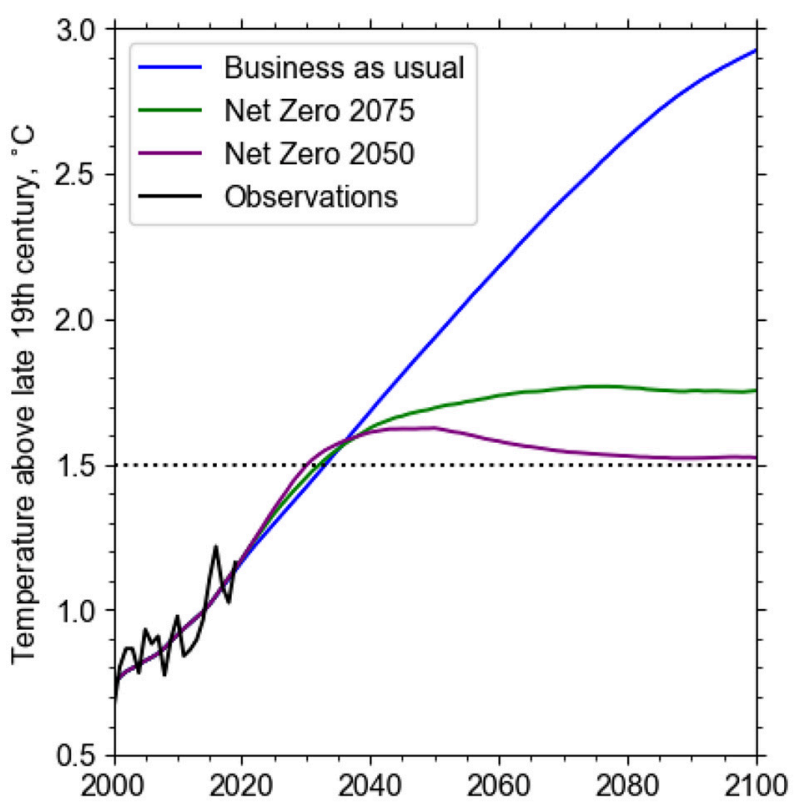

Figure 1

\section{OUR FUTURE CLIMATE}

In 2015, almost every country in the world signed up for the Paris Agreement. The aim of this agreement is to limit global warming by keeping the world's average temperature increase to below $2^{\circ} \mathrm{C}$ (and hopefully only $1.5^{\circ} \mathrm{C}$ ) above the average temperature of the late Nineteenth century. This level of warming sounds small, but it could cause big problems. Scientists know that climate extremes like floods, heatwaves, and droughts become more likely and worse with more warming. These weather events can lead to crop shortages and increased food prices, which could cause more people to go hungry. Sea levels will rise because of melting land ice and the expansion of warmer ocean water. This will put millions of people in coastal cities and small islands at risk. The more warming that occurs, the greater these impacts will be. Every tenth of a degree matters.

The planet has already warmed by $1.2^{\circ} \mathrm{C}$ since the late Nineteenth century and the effects have already been felt. To have a good chance of keeping global warming below $1.5^{\circ} \mathrm{C}$, we need to reduce our emissions of carbon dioxide $\left(\mathrm{CO}_{2}\right)$ by half by 2030, and then reduce emissions to zero by 2050 (Figure 1). These are ambitious targets that require urgent and wide-ranging changes in our society and economy. The pledges made by countries in the Paris Agreement are not currently enough to meet these targets and will result in around $3^{\circ} \mathrm{C}$ of warming by the end of the century (blue line in Figure 1 ).

The good news is that the future climate change we see is mostly based on the choices we make today. However, these choices are not easy, and the speed at which we must change our world to limit climate change is unlike anything we have seen before. 
NEGATIVE

EMISSIONS

$\mathrm{CO}_{2}$ removal from the atmosphere.

NET ZERO

EMISSIONS

The amount of $\mathrm{CO}_{2}$ emitted equals the amount of $\mathrm{CO}_{2}$ removed from the atmosphere through natural or artificial methods.

\section{CARBON}

\section{FOOTPRINT}

Amount of greenhouse gases released to the atmosphere as a result of our daily activities. It is measured in equivalent tonnes of $\mathrm{CO}_{2}$ per person and year.

Most human activities involve burning fossil fuels for energy, which releases $\mathrm{CO}_{2}$. In 2019, we emitted 42 billion tonnes of $\mathrm{CO}_{2}$. Despite the coronavirus crisis, emissions only dropped by $7 \%$ in 2020 [1]. Moving to renewable energy sources (such as wind turbines and solar power) and switching road vehicles from petrol and diesel to electric power will help us reduce $\mathrm{CO}_{2}$ emissions. In addition, we may need to remove $\mathrm{CO}_{2}$ from the atmosphere, a process that is called negative emissions. Reaching net zero emissions globally-which means that we remove from the atmosphere the same amount of $\mathrm{CO}_{2}$ that we emit-will take individual and collective action.

\section{WHAT CAN WE DO?}

There are several things you can do as an individual to reduce your impact on the climate. The amount of $\mathrm{CO}_{2}$ that each one of us emits to the atmosphere every year is known as a carbon footprint. On average, each person in the world emits 6.7 tonnes of $\mathrm{CO}_{2}$ per year, but this varies widely within and between countries. Generally, richer people in richer countries are responsible for most of the $\mathrm{CO}_{2}$ emitted. Research has shown that the amount of energy required to live comfortably is in fact quite low [2]. If everybody in the world had this same comfortable standard of living, it would result in an improvement in quality of life for billions of people in the developing world, but would require rich people and rich countries to consume and waste less.

Towns and cities should be designed to be more friendly to walking, cycling, and public transport. Changing the way we travel is the most powerful action we can take to reduce our carbon footprints. For example, living car-free can save up to 5 tonnes of $\mathrm{CO}_{2}$ emitted per person every year [3], and it is also good for your health and the local air quality. A long-distance flight adds a lot of $\mathrm{CO}_{2}$ to the atmosphere. This can be reduced by taking a train whenever possible or by going on holidays closer to home. Towns should have good transport links and be built or modified to be more energy efficient, so that they are easier to keep cool in the summer and warm in the winter.

We can also reduce our impact on the climate by being careful where we spend our money. Try to buy only from companies that are sustainable and do not compromise the environment. For example, try to buy electricity from a provider that uses 100\% renewable energy. Renewable energy companies get their energy from solar panels and wind turbines. Switching on the lights and heat at home only when necessary also helps reduce our emissions-and our bills! Eating less meat (especially beef) and dairy and avoiding food waste are also powerful individual actions that can save up to two additional tonnes of $\mathrm{CO}_{2}$ emissions per person per year. 
Individual actions will only go so far, and we should not feel badly if our lifestyles do not allow some of them. For example, not everyone can afford an electric car or to put solar panels on the roof. However, remember that your actions can inspire others. Use your voice! Talking about climate change with your friends, family, and classmates really helps to raise awareness and drive further action.

Large businesses, city/state leaders, and national governments are the organisations that can make the big changes we need. How do we influence them? There are multiple ways to make elected governments hear your voice. Educate yourself on the climate commitments for each candidate or political party in your town, city, or country. Discuss climate issues with the adults in your life, because this may help influence the way they vote. And use your vote when you are old enough! Even if you are not old enough to vote, you can have a huge influence. The \#Fridays4Future school strike movement, started by then 16-year-old Greta Thunberg, helped communicate some of the anger that young people are feeling about inaction on climate change.

Mass protests around the world have raised awareness of the climate crisis in the political arena. Many local and state governments have now acknowledged the issue and declared a "climate emergency" that requires urgent action. Collective action has been shown to be very useful. It is only at the society level that we will be able to make changes for a better future.

At the national level, countries are making transitions toward clean energy sources and pledging to become net zero (Figure 2). These countries must quickly reduce their emissions of greenhouse gases, and unavoidable emissions (like those from aeroplanes) should be balanced by negative emissions. Whether the world is ultimately successful at reaching net zero by 2050 depends on making sure more countries commit to their own targets and work hard to achieve them.

\section{CAN NEGATIVE EMISSIONS REVERSE CLIMATE CHANGE?}

There are two reasons why we might try to remove $\mathrm{CO}_{2}$ from the atmosphere. First, the total warming the Earth has experienced is closely related to the total amount of $\mathrm{CO}_{2}$ that has ever been emitted [5], so there is a possibility we might be able to reverse warming in the future, with net-negative emissions. The second reason relates to net zero emissions: it is hard to avoid $\mathrm{CO}_{2}$ emissions caused by some activities, like flying. While we need to reduce the amount we fly, it is unlikely that we will stop flying completely in the future, so we need a way to "cancel out" the positive emissions from flying. 
Figure 2

Target dates to become net zero. Suriname and Bhutan (pink) are currently carbon negative. Countries in green have made legally binding pledges to become net zero by 2045 or 2050. Small island states have proposed legislation to achieve net zero by 2050 (Data from [4], last updated in December 2020).

CARBON CAPTURE AND STORAGE

Nature-based process by which $\mathrm{CO}_{2}$ is taken from the atmosphere and stored in a safe location (like geological formations) where it is not harmful for the climate system or the ecosystems.

\section{BIO-ENERGY WITH} CARBON CAPTURE AND STORAGE

Nature-based alternative to fossil fuels consisting of planting trees to later burn them, generating a lot of energy. The $\mathrm{CO}_{2}$ released in the process is captured and kept away from the atmosphere

DIRECT AIR

CARBON CAPTURE AND STORAGE

Human-created solution to remove $\mathrm{CO}_{2}$ from the atmosphere via "hoovering" large amounts of air and storing $\mathrm{CO}_{2}$ underground.

\section{CARBON}

SEQUESTRATION

Process through which plants capture $\mathrm{CO}_{2}$ from the atmosphere and store it in the soil.

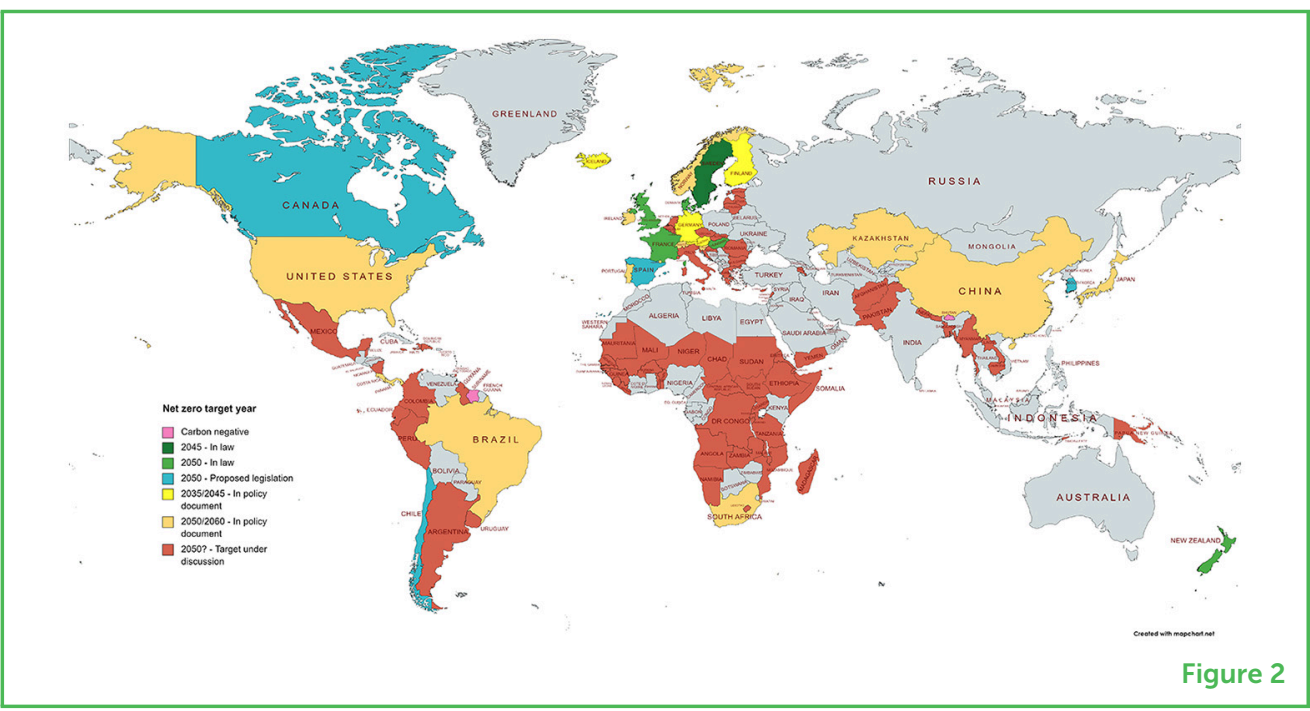

There are several nature-based and human-created ways to remove $\mathrm{CO}_{2}$ from the atmosphere where it affects climate. Some examples are shown in Figure 3. One idea is to capture and bury $\mathrm{CO}_{2}$ underground in unused oil wells and geological formations, storing it away from the atmosphere. This is known as carbon capture and storage (CCS). Planting trees is a good idea too, because trees suck up $\mathrm{CO}_{2}$ and release oxygen when they perform photosynthesis. We could even grow trees to burn for fuel (instead of using fossil fuels), and then capture the $\mathrm{CO}_{2}$ that is released. This is known as bio-energy with carbon capture and storage (BECCS). BECCS is a negative-emissions method because the carbon in the tree material was already in the atmosphere, and then we capture and remove it. BECCS has the potential to remove about a quarter of our current total emissions by 2050. $\mathrm{CO}_{2}$ can also be "vacuumed" directly from the atmosphere and stored underground, a process known as direct air carbon capture and storage (DACCS).

Trees naturally remove $\mathrm{CO}_{2}$ from the atmosphere, so planting more trees and could cancel out another 5.5 billion tonnes of $\mathrm{CO}_{2}$. Through carbon sequestration, plants naturally capture carbon from the atmosphere and store it in the soil. Burning trees and plants in the absence oxygen also helps to store $\mathrm{CO}_{2}$ in a solid form for thousands of years, keeping it away from the atmosphere. The resulting product is called biochar. Although a large amount of $\mathrm{CO}_{2}$ is released in the biochar process, it still might be a powerful source of negative emissions in the medium-to-long term. Biochar can also be used as a fertiliser to help crops grow.

There are several drawbacks to these methods of removing $\mathrm{CO}_{2}$ from the atmosphere. DACCS technology is currently very expensive and uses a lot of energy. Solutions based on trees and plants require lots of land, which is limited and could reduce the amount of land available to grow food. Food shortages could increase food prices 
Figure 3

Potential of various solutions to remove atmospheric $\mathrm{CO}_{2}$ by 2050. Units are billions of tonnes of $\mathrm{CO}_{2}$ per year (Adapted from Minx et al. [6]).

\section{BIOCHAR}

Waste product obtained by burning trees and plants in the absence of oxygen.

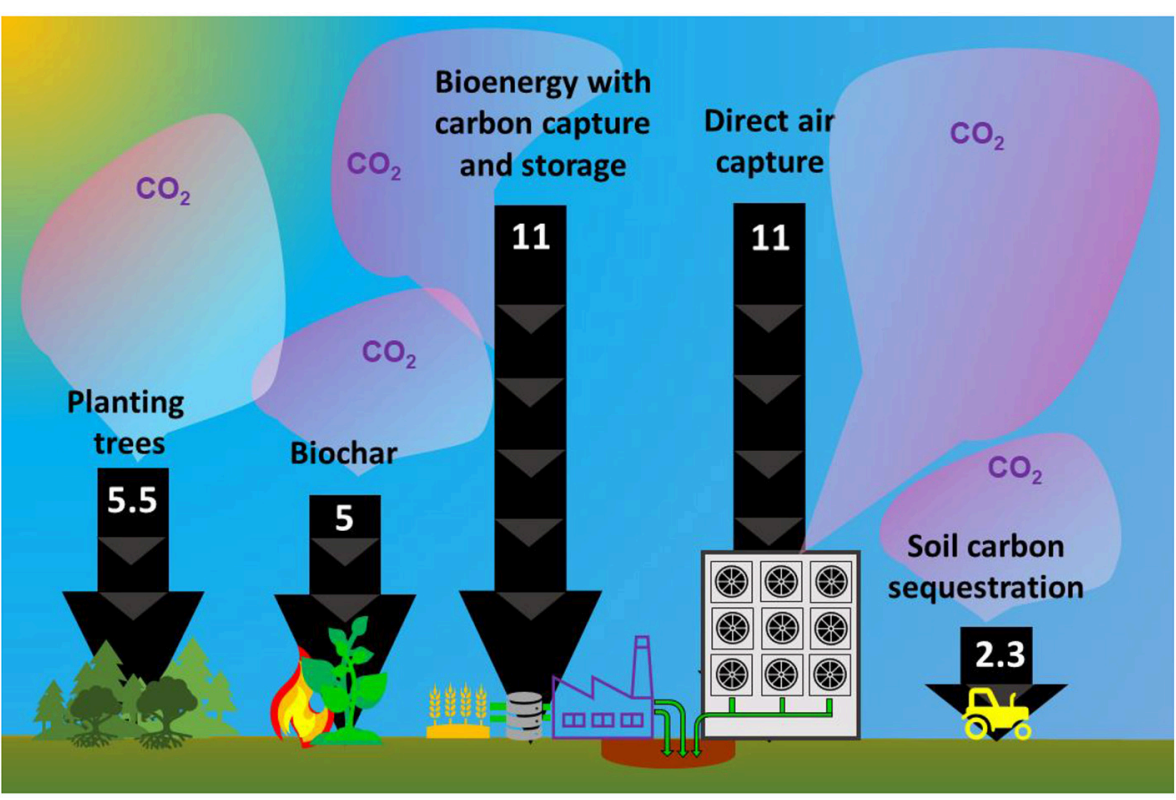

Figure 3

and more people could go hungry. Successfully removing carbon from the atmosphere will require cooperation between countries and people, and the willingness of governments to make big, expensive investments in carbon-capture technologies.

Even if all the potential negative emissions methods were used, they still would not be enough to reach net zero $\mathrm{CO}_{2}$ with our current emissions of 42 billion tonnes per year. Therefore, negative emissions are not a miracle cure-we still need to reduce our emissions in other ways, too.

It is up to us whether we avoid the worst consequences of global warming. Talking about climate change is the most effective way to get everyone on board. We all need to work hard to achieve net-zero by 2050 at the individual and collective level. Remember: every tenth of a degree matters!

\section{REFERENCES}

1. Friedlingstein, P., O'Sullivan, M., Jones, M. W., Andrew, R. M., Hauck, J., Olsen, A., et al. 2020. Global Carbon Budget 2020. Earth Syst Sci Data. 12:3269-340. doi: 10.5194/essd-12-3269-2020

2. Millward-Hopkins, J., Steinberger, J. K., Rao, N. D., and Oswald, Y. 2020. Providing decent living with minimum energy: a global scenario. Glob Environ Change. 65:102168. doi: 10.1016/j.gloenvcha.2020.102168

3. Wynes, S., and Nicholas, K. A. 2017. The climate mitigation gap: education and government recommendations miss the most effective individual actions. 
Environ Res Lett. 12:074024. Available online at: https://iopscience.iop. org/article/10.1088/1748-9326/aa7541?TB_iframe=true\&width=921.68 height $=921.6$

4. Energy \& Climate Intelligence Unit. 2020. Countdown to Zero Plotting Progress Towards Delivering Net Zero Emissions by 2050. Available online at: https:// ca1-eci.edcdn.com/reports/ECIU_Countdown_to_Net_Zero.pdf (accessed January 4, 2021).

5. Allen, M. R., Frame, D. J., Huntingford, C., Jones, C. D., Lowe, J. A., Meinshausen, M., et al. 2009. Warming caused by cumulative carbon emissions towards the trillionth tonne. Nature. 458:1163-6. doi: 10.1038/nature08019

6. Minx, J. C., Lamb, W. F., Callaghan, M. W., Fuss, S., Hilaire, J., Creutzig, F., et al. 2018. Negative emissions-Part 1: research landscape and synthesis. Environ Res Lett. 13:063001. Available online at: https://iopscience.iop.org/article/10.1088/ 1748-9326/aabf9b

SUBMITTED: 26 February 2021; ACCEPTED: 13 September 2021; PUBLISHED ONLINE: 14 October 2021.

EDITOR: Chris Jones, Met Office Hadley Centre (MOHC), United Kingdom

CITATION: Trascasa-Castro P and Smith CJ (2021) What Can We Do to Address Climate Change? Front. Young Minds 9:672854. doi: 10.3389/frym.2021.672854

CONFLICT OF INTEREST: The authors declare that the research was conducted in the absence of any commercial or financial relationships that could be construed as a potential conflict of interest.

COPYRIGHT (c) 2021 Trascasa-Castro and Smith. This is an open-access article distributed under the terms of the Creative Commons Attribution License (CC BY). The use, distribution or reproduction in other forums is permitted, provided the original author(s) and the copyright owner(s) are credited and that the original publication in this journal is cited, in accordance with accepted academic practice. No use, distribution or reproduction is permitted which does not comply with these terms.

\section{YOUNG REVIEWER}

\section{EVA, AGE: 15}

I am Eva I still go to school and I enjoy subjects like science and I also really like art. I love to draw, play video games and to meet my friends.

\section{AUTHORS}

\section{PALOMA TRASCASA-CASTRO}

Paloma is Ph.D. student at the University of Leeds, researching how the atmosphere and the ocean communicate with each other. She is very interested in understanding how the climate system works and how it responds to an increase in temperatures associated with global warming. Together with other Ph.D. students, she runs 


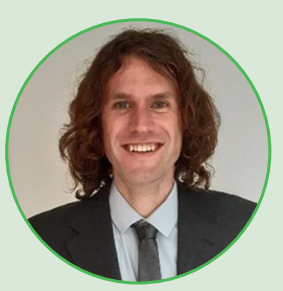

"The Climate Press," a podcast and blog series that aims to make climate science understandable by everyone. In her free time, she enjoys playing music and hiking with friends! *ee17pt@leeds.ac.uk

\section{CHRISTOPHER J. SMITH}

Chris Smith's research interests include using simple climate models to investigate climate impacts from a wide range of emissions scenarios. Chris received his Ph.D. from the University of Leeds in 2016, studying how solar energy resources may be affected by climate change in the future. From 2016 to 2020, he worked as a research fellow at the University of Leeds on climate change. Chris enjoys running, cycling, and being outdoors. 